\title{
Erratum to: Congenital pericardial defect: a case of right pericardial partial absence with normal parietal pleura
}

\author{
Shun Ono $\cdot$ Tamaki Ichikawa $\cdot$ Misako Iino $\cdot$ Yuri Yamada \\ Tatsuya Sekiguchi $\cdot$ Tomoki Nakagawa $\cdot$ Naohiro Aruga $\cdot$ \\ Masayuki Iwazaki · Dai Joishi · Yutaka Imai
}

Published online: 18 February 2015

(C) Japan Radiological Society 2015

\section{Erratum to: Jpn J Radiol}

DOI 10.1007/s11604-014-0387-9

There was an error in the published title of this article. The correct title is "Congenital pericardial defect: a case of right pericardial partial absence with normal parietal pleura".

The online version of the original article can be found under doi:10.1007/s11604-014-0387-9.

\footnotetext{
S. Ono $(\bowtie) \cdot$ T. Ichikawa $\cdot$ M. Iino $\cdot$ Y. Yamada $\cdot$ T. Sekiguchi $\cdot$

D. Joishi · Y. Imai

Department of Radiology, Tokai University School of Medicine,

143 Shimokasuya, Isehara, Kanagawa 259-1193, Japan

e-mail: onsn25@outlook.jp

T. Ichikawa

e-mail: tamaki-i@is.icc.u-tokai.ac.jp

M. Iino

e-mail: misaiino@hotmail.com

Y. Yamada

e-mail: yuri-714@is.icc.u-tokai.ac.jp

T. Sekiguchi

e-mail: jpygw100@gmail.com
}

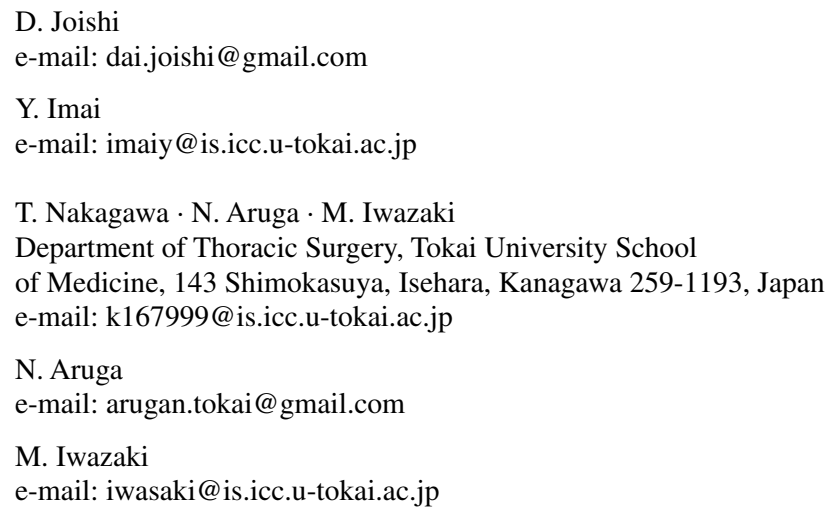

